\title{
Sex-related gene expression profiles in the adrenal cortex in the mature rat: Microarray analysis with emphasis on genes involved in steroidogenesis
}

\author{
MARCIN TREJTER, ANNA HOCHOL, MARIANNA TYCZEWSKA, AGNIESZKA ZIOLKOWSKA, \\ KAROL JOPEK, MARTA SZYSZKA, LUDWIK K. MALENDOWICZ and MARCIN RUCINSKI \\ Department of Histology and Embryology, Poznan University of Medical Sciences, Poznan, Poland
}

Received November 7, 2014; Accepted January 9, 2015

DOI: $10.3892 / \mathrm{ijmm} .2015 .2064$

\begin{abstract}
Notable sex-related differences exist in mammalian adrenal cortex structure and function. In adult rats, the adrenal weight and the average volume of zona fasciculata cells of females are larger and secrete greater amounts of corticosterone than those of males. The molecular bases of these sex-related differences are poorly understood. In this study, to explore the molecular background of these differences, we defined zoneand sex-specific transcripts in adult male and female (estrous cycle phase) rats. Twelve-week-old rats of both genders were used and samples were taken from the zona glomerulosa (ZG) and zona fasciculata/reticularis (ZF/R) zones. Transcriptome identification was carried out using the Affymetrix ${ }^{\circledR}$ Rat Gene 1.1 ST Array. The microarray data were compared by fold change with significance according to moderated t-statistics. Subsequently, we performed functional annotation clustering using the Gene Ontology (GO) and Database for Annotation, Visualization and Integrated Discovery (DAVID). In the first step, we explored differentially expressed transcripts in the adrenal ZG and ZF/R. The number of differentially expressed transcripts was notably higher in the female than in the male rats (702 vs. 571). The differentially expressed genes which were significantly enriched included genes involved in steroid hormone metabolism, and their expression levels in the $\mathrm{ZF} / \mathrm{R}$ of adult female rats were significantly higher compared with those in the male rats. In the female $\mathrm{ZF} / \mathrm{R}$, when compared with that of the males, prevailing numbers of genes linked to cell fraction, oxidation/reduction processes, response to nutrients and to extracellular stimuli or steroid hormone stimuli were downregulated. The microarray data for key genes involved
\end{abstract}

Correspondence to: Professor Ludwik K. Malendowicz, Department of Histology and Embryology, Poznan University of Medical Sciences, 6 Swiecicki St., 60-781 Poznan, Poland

E-mail: 1km@ump.edu.pl

Key words: rat, adrenal cortex, transcriptome, gene profiling, functional annotation clustering, sex differences directly in steroidogenesis were confirmed by qPCR. Thus, when compared with that of the males, in the female $\mathrm{ZF} / \mathrm{R}$, higher expression levels of genes involved directly in steroid hormone synthesis were accompanied by lower expression levels of genes regulating basal cell functions.

\section{Introduction}

It is well known that adult female rats have heavier adrenal glands than males of the same age. This difference appears only after puberty and is dependent upon sex hormones. Earlier, mainly morphologic, cytological and gravimetric data on this subject had been extensively reviewed by Bachmann in 1954 (1). In the rat, adrenal sex dimorphism is accompanied by functional differences, with females secreting greater amounts of corticosterone than males (reviewed in refs. 2-5). Furthermore, female rats show greater adrenocorticotropic hormone (ACTH) and corticosterone responses to stress and these hormonal responses are modified by gonadectomy and gonadal hormone replacement (6-8). Numerous studies have suggested that observed sex differences in the rat adrenal structure and function are dependent on the inhibitory effects of testosterone on the hypothalamo-pituitary-adrenal (HPA) axis, while estrogens exert opposite effects (reviewed in refs. 4-5,9-12). However, the molecular bases of the above outlined sex-related differences in rat adrenal cortex structure and function have not yet been fully elucidated.

The introduction of gene expression microarray technology opens the possibility of discovering genes that may contribute to various biological effects. As regards the adrenal gland, an example of such a study is the identification of genomewide changes in gene expression following the treatment of Y1 mouse adrenocortical cells with ACTH (13). In this cell line, ACTH affected the levels of 1,275 different transcripts, and only 133 were previously known as corticotropinaffected. Moreover, the authors demonstrated that the cAMP/ protein kinase $\mathrm{A}$ and protein kinase $\mathrm{C}$ pathways appeared to account for approximately $60 \%$ of the effects of ACTH (13). Furthermore, by means of laser-capture microdissection, Nishimoto et al $(14,15)$ identified hundreds of transcripts with differential expression in the zona glomerulosa $(\mathrm{ZG})$ and zona fasciculata $(\mathrm{ZF})$ of adult male rats. 
As far as sex-related differences in the adrenal cortex are concerned, recently, El Wakil et al performed a genomic analysis of gene expression in the mouse adrenal gland (16). In their data, not considering the transcription factors, nuclear receptor subfamily 5 , group $\mathrm{A}$, member 1 (Nr5a1) and nuclear receptor subfamily 0 , group $B$, member 1 (NrOb1), none of the genes directly involved in steroid hormone biosynthesis showed a differential expression in the male and female mouse adrenal glands (16).

Therefore, in the present study, using the adrenal glands of mature male and female rats, we performed whole transcriptome analyses that allowed us to compare the expression levels of approximately 27,000 genes by applying microarray technology. Gene expression analyses were performed separately on $\mathrm{ZG}$ and $\mathrm{ZF} /$ reticularis $(\mathrm{ZF} / \mathrm{R})$ samples. In the $\mathrm{ZG}$, we revealed 32 differentially expressed genes, while 233 such genes were found in the $\mathrm{ZF} / \mathrm{R}$. The functional profiles of the differentially (male/female) expressed genes were characterized by means of the GeneAnswers package of Bioconductor or by the Database for Annotation, Visualization and Integrated Discovery (DAVID) tool, as previously described $(17,18)$. Both methods revealed functional profiles of the differentially (male/ female) expressed genes and their role in the rat adrenal gland was analyzed.

\section{Materials and methods}

Animals. Adult female and male Wistar rats (12 weeks old; final body weight, 120-150 g) were obtained from the Laboratory Animals Breeding Center, Department of Toxicology, Poznan University of Medical Sciences, Poznan, Poland. The animals were maintained under standardized conditions of light (14:10 h light-dark cycle, illumination onset 06.00$)$ at $23^{\circ} \mathrm{C}$ with free access to standard food pellets and tap water. Female rats were used in the estrous cycle phase, which was determined according to the cell types observed in the vaginal smear. Following decapitation (between 09:00 and 10:00), the adrenal glands were promptly removed, freed of adherent fat and processed for analysis. Briefly, under a stereomicroscope, the male and female (both groups, $n=6$ ) rat adrenal glands were decapsulated to separate the $\mathrm{ZG}$ from the $\mathrm{ZF} / \mathrm{R}$. The medulla of the adrenal gland was removed and was not used in our analysis. The Local Ethics Committee for Animal Studies at the Poznan University of Medical Sciences approved the study protocol. Unless otherwise stated, all reagents were obtained from Sigma-Aldrich (St. Louis, MO, USA) or from Avantor Performance Materials Poland S.A. (Gliwice, Poland).

RNA isolation. RNA isolation from samples of adrenal glands was carried out as previously described (19-23). Briefly, we used TRI reagent (Sigma-Aldrich) and the isolated RNA was purified on columns (RNeasy mini kit; Qiagen, Hilden, Germany). The quantity of the total RNA was determined spectrophotometrically (optical density at $260 \mathrm{~nm}$ ) and its purity was estimated by a $260 / 280 \mathrm{~nm}$ absorption ratio $(>1.8)$ (NanoDrop spectrophotometer; Thermo Scientific, Waltham, MA, USA). RNA integrity and quality were examined using the Bioanalyzer 2100 (Agilent Technologies, Inc., Santa Clara, CA, USA). Evaluated RNA Integrity Numbers (RINs) were between 8.5 and 10 with the average of 9.2. The RNA concentration in each sample was diluted to $100 \mathrm{ng} / \mu \mathrm{l}$ with an OD260/OD280 ratio of 1.8/2.0.

Microarray analysis. Microarray analysis was carried out as previously described (21-23). Isolated total RNA (100 ng) was mixed with $1.5 \mu \mathrm{l}$ of Poly-A RNA control solution and subjected to reverse transcription. The obtained cDNA was used for in vitro transcription to prepare antisense RNA (aRNA) by incubation at $40^{\circ} \mathrm{C}$ for $16 \mathrm{~h}$. Following purification, the aRNA was applied for the second round of sense cDNA synthesis using the WT Expression kit (Ambion, Austin, TX, USA). All subsequent steps were performed using the Affimetrix microarray system (Affymetrix, Santa Clara, CA, USA). The obtained cDNA was used for biotin labeling and fragmentation by Affymetrix GeneChip ${ }^{\circledR}$ WT Terminal Labeling and Hybridization. Biotin-labeled fragments of cDNA $(5.5 \mu \mathrm{g})$ were hybridized to the Affymetrix ${ }^{\circledR}$ Rat Gene 1.1 ST Array Strip $\left(45^{\circ} \mathrm{C} / 24 \mathrm{~h}\right)$. Each array comprised of $>720,000$ unique 25 -mer oligonucleotide probes, which included $>27,000$ genes. Up to 25 unique probes sequences were hybridized to a single transcript. Following hybridization, each array strip was washed and stained using the Fluidics Station of GeneAtlas system (Affymetrix). The array strips were scanned using the Imaging Station of the GeneAtlas system. A preliminary analysis of the scanned chips was performed using Affymetrix GeneAtlas ${ }^{\mathrm{TM}}$ Operating Software. The quality of gene expression data was examined according to the quality control criteria provided with the software. The intensity of fluorescence was converted to numerical data by generating CEL files. The obtained CEL files were imported into downstream data analysis software. Unless otherwise stated, all presented analyses and graphs were performed using Bioconductor and $\mathrm{R}$ programming language, as previously described (24). Each CEL file was merged with a description file (downloaded from the Affymetrix webpage). In order to perform background correction, normalization and summarization of the results, we used the Robust Multiarray Averaging (RMA) method. The statistical significance of the analyzed genes was examined by moderated t-statistics from the empirical Bayes method. The obtained p-values were corrected for multiple comparisons using the Benjamini and Hochberg's false discovery rate (statistical method incorporated into Bioconductor calculations) (25). The selection of genes with a significant change in expression was based on a p-value $<0.05$ and an expression fold change $\geq 2$. Fold change calculations were performed either for appropriate zones of male and female rats or for the $\mathrm{ZG}$ and $\mathrm{ZF} / \mathrm{R}$ of adrenal glands in both genders (Fig. 1).

Functional analysis by GeneAnswer. Singular enrichment analysis (SEA) was performed as previously described $(15,26,27)$. Selected sets of differentially expressed genes were applied to functional analysis using the GeneAnswers package of Bioconductor which, among other, allows us to interpret a list of genes in the context of their participation in particular biological processes (GO.BP) (28). Gene ontology analyses were also performed using the web deposited manual (http:// www.bioconductor.org/packages/release/bioc/vignettes/Gene Answers/inst/doc/geneAnswers.pdf). Lists of differentially expressed genes were combined as tables and were subjected to further analyses. Since our dataset comprised 2 comparison 
Table I. Primers used for the RT-qPCR validation of selected genes.

\begin{tabular}{|c|c|c|c|c|c|}
\hline $\begin{array}{l}\text { Gene } \\
\text { symbol }\end{array}$ & Gene name & $\begin{array}{c}\text { GenBank } \\
\text { accession no. }\end{array}$ & $\begin{array}{l}\text { Primer sequences } \\
\qquad\left(5^{\prime} \rightarrow 3^{\prime}\right)\end{array}$ & Position & $\begin{array}{l}\text { PCR product } \\
\text { size (bp) }\end{array}$ \\
\hline Star & $\begin{array}{l}\text { Steroidogenic acute } \\
\text { regulatory protein }\end{array}$ & NM_031558 & $\begin{array}{l}\text { CCTGAGCAAAGCGGTGTCAT } \\
\text { GCAAGTGGCTGGCGAACTCTA }\end{array}$ & $\begin{array}{l}745-764 \\
911-931\end{array}$ & 187 \\
\hline Cyp11a1 & $\begin{array}{l}\text { Cytochrome } \mathrm{P} 450 \text {, family } 11 \text {, } \\
\text { subfamily a, polypeptide } 1\end{array}$ & NM_017286 & $\begin{array}{l}\text { GATGACCTATTCCGCTTTGC } \\
\text { GTTGGCCTGGATGTTCTTG }\end{array}$ & $\begin{array}{l}592-611 \\
930-948\end{array}$ & 357 \\
\hline Cyp11b1 & $\begin{array}{l}\text { Cytochrome } \mathrm{P} 450 \text {, family } 11 \text {, } \\
\text { subfamily b, polypeptide } 1\end{array}$ & NM_012537.3 & $\begin{array}{l}\text { TCATATCCGAGATGGTAGCAC } \\
\text { CTTCTGGGGATTAGCAACGA }\end{array}$ & $\begin{array}{l}863-883 \\
1049-1068\end{array}$ & 206 \\
\hline Cyp11b2 & $\begin{array}{l}\text { Cytochrome P450, family } 11 \text {, } \\
\text { subfamily b, polypeptide } 2\end{array}$ & NM_012538.2 & $\begin{array}{l}\text { TGGCAGCACTAATAACTCAGG } \\
\text { AAAAGCCACCAACAGGGTAG }\end{array}$ & $\begin{array}{l}875-895 \\
1131-1150\end{array}$ & 276 \\
\hline Lipe & Hormone-sensitive lipase & NM_012859.1 & $\begin{array}{l}\text { GCCCTCCAAACAGAAACCC } \\
\text { AAATCCATGCTGTGTGAGAA }\end{array}$ & $\begin{array}{l}967-985 \\
1082-1101\end{array}$ & 135 \\
\hline NrOb1 & $\begin{array}{l}\text { Nuclear receptor subfamily } 0 \text {, } \\
\text { group B, member } 1\end{array}$ & NM_053317.1 & $\begin{array}{l}\text { AGAGTACGCCTATCTGAAG } \\
\text { ATCGGTGTTGATGAATCTC }\end{array}$ & $\begin{array}{l}1141-1159 \\
1321-1339\end{array}$ & 199 \\
\hline Hcrtr2 & Hypocretin (orexin) receptor 2 & NM_013074.1 & $\begin{array}{l}\text { GGCTTATCTCCAAATATTCCGTAA } \\
\text { CTCTGAACCACAGAAGAAGTTCC }\end{array}$ & $\begin{array}{l}782-806 \\
828-850\end{array}$ & 69 \\
\hline Hprt & $\begin{array}{l}\text { Hypoxanthine } \\
\text { phosphoribosyltransferase }\end{array}$ & NM_012583 & $\begin{array}{l}\text { ATTTTGGGGCTGTACTGCTTGA } \\
\text { CAGTCAACGGGGGACATAAAAG }\end{array}$ & $\begin{array}{l}391-412 \\
515-536\end{array}$ & 146 \\
\hline
\end{tabular}

Gene symbol, gene names, GeneBank accession numbers, oligonucleotide sequences for sense and antisense primers, their position on mRNA and product size are shown. Hprt was used as a reference gene.

sets (male vs. female ZG and male vs. female ZF/R) we performed multigrup gene analyses. The GeneAnswers package allowed to test the enrichment of each GO.BP category in a gene list using a well-defined hypergeometric statistical test. The p-value was determined based on the number of genes differentially expressed in the investigated GO category. This test was performed separately for the $\mathrm{ZG}$ and $\mathrm{ZF} / \mathrm{R}$ and the results are presented in the respective figures.

Functional analysis by DAVID. The other analysis was performed by functional annotation clustering using DAVID. This database provides functional annotation tools for understanding the biological meaning behind a large list of genes (www.david.abcc.ncifcrf.gov). Among the many functions, DAVID allows us to discover enriched function-related gene groups and to cluster similar annotation terms $(17,18)$.

All procedures were performed according to the web provided manual (http://david.abcc.ncifcrf.gov/content. jsp?file=functional_annotation.html). The official symbols of genes which were differentially expressed (both in male and female ZG and ZF/R) were loaded separately into DAVID as a gene list. Annotations and background (total number of genes in the rat) were limited only to Rattus norvegicus. In order to obtain the most meaningful clusters, the threshold of EASE score (a modified Fisher exact p-Value) for gene enrichment analysis was set $\leq 0.05$. Again, the obtained $p$-values were corrected for multiple comparisons using the Benjamini and Hochberg's false discovery rate (25). Analyses were performed separately for the $\mathrm{ZG}$ and $\mathrm{ZF} / \mathrm{R}$ zones of the adult male and female rats, as indicated in the descriptions provided with the figures and tables.
Validation by RT-qPCR. The methods applied for RT-qPCR were as described in previous studies (19-23). Reverse transcription was performed using AMV reverse transcriptase (Promega Corp., Madison, WI, USA) with Oligo(dT) (PE Biosystems, Warrington, UK) as primers in the temperature of $42^{\circ} \mathrm{C}$ for $60 \mathrm{~min}$ (Thermocycler UNO II; Biometra, Goettingen, Germany). The primers used were designed by Primer 3 software (Whitehead Institute for Biomedical Research, Cambridge, UK) (Table I). The primers were purchased from the Laboratory of DNA Sequencing and Oligonucleotide Synthesis, Institute of Biochemistry and Biophysics, Polish Academy of Sciences, Warsaw, Poland. qPCR was performed using the Lightcycler 2.0 instrument (Roche Diagnostics Corp., Indianapolis, IN, USA) with the 4.05 software version. Using the above-mentioned primers, the SYBR-Green detection system was applied. Each $20 \mu 1$ reaction mixture contained $4 \mu 1$ template cDNA (standard or control), $0.5 \mu \mathrm{M}$ of each gene-specific primer and a previously determined optimum $\mathrm{MgCl}_{2}$ concentration (3.5 $\mu \mathrm{M}$ for one reaction). LightCycler FastStart DNA Master SYBR-Green I mix (Roche Diagnostics Corp.) was used. The real-time PCR program included a 10-min denaturation step to activate the TaqDNA polymerase, followed by a 3-step amplification program: denaturation at $95^{\circ} \mathrm{C}$ for $10 \mathrm{sec}$, annealing at $56^{\circ} \mathrm{C}$ for $5 \mathrm{sec}$, and extension at $72^{\circ} \mathrm{C}$ for $10 \mathrm{sec}$. The specificity of the reaction products was examined by the determination of the melting points $\left(0.1^{\circ} \mathrm{C} / \mathrm{sec}\right.$ transition rate).

Statistical analysis. The RT-qPCR data are expressed as the means $\pm \mathrm{SE}$, and the statistical significance of the differences 

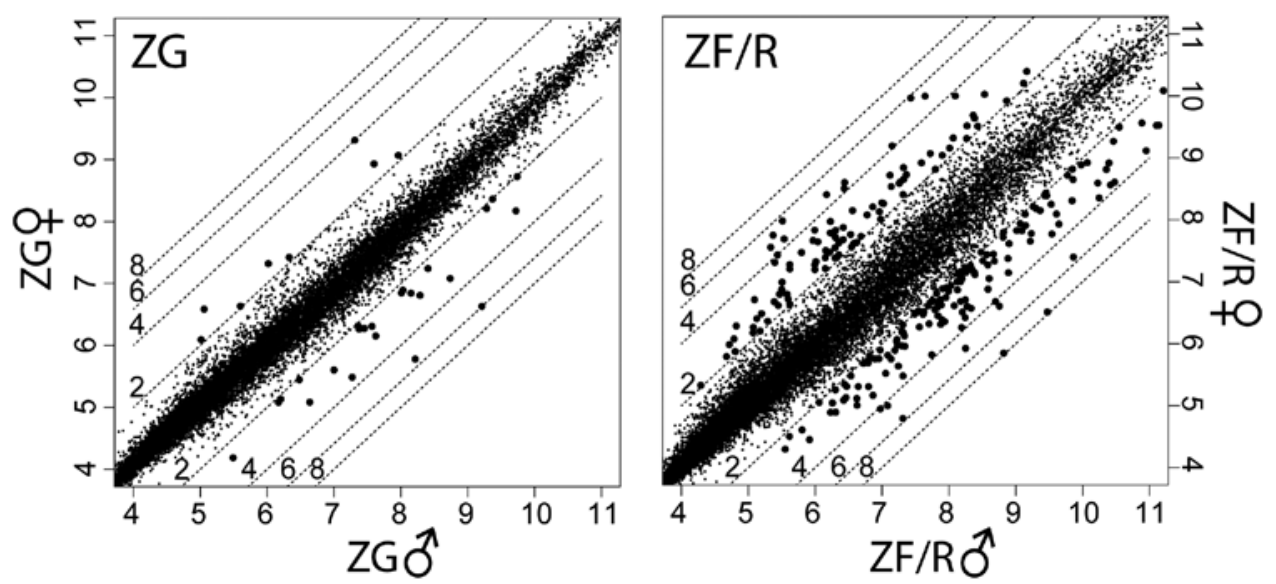

Figure 1. Scatter plot graphs of gender-specific differences in gene expression in the ZG and ZF/R of adrenal glands of adult female rats, in comparison to adult male rats (Affymetrix ${ }^{\circledR}$ Rat Gene 1.1 ST Array). Dotted lines indicate cut-off values (2,4,6,8 fold change in expression). The left upper part of the graphs indicates higher expression levels in the female compared to the male adrenal glands; the right lower part of the graph indicates lower expression levels in the female compared to the male adrenal glands (differences in expression $\geq 2 ; \mathrm{p}<0.05$ ). Names of genes are not shown. ZG, zona glomerulosa; $\mathrm{ZF} / \mathrm{R}$, zona fasciculata/reticularis

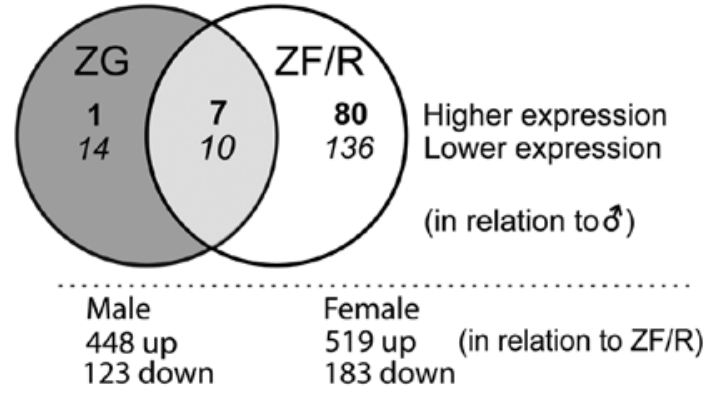

Figure 2. Venn diagram of differentially expressed genes in the ZG and $\mathrm{ZF} / \mathrm{R}$ of adrenal glands of adult female rats, in comparison to adult male rats Middle section shows the number of genes which had similar expression patterns in both zones. Bold font indicates higher expression levels; italic font indicates lower expression levels. In the lower part of figure, the numbers of genes differentially expressed in the $\mathrm{ZG}$, in comarison to the $\mathrm{ZF} / \mathrm{R}$ are shown (separately for adrenal glands of adult male and female rats. ZG, zona glomerulosa; ZF/R, zona fasciculata/reticularis).

between the control and experimental groups was estimated using the Student's t-test. A p-value $<0.05$ was considered to indicate a statistically signficiant difference.

\section{Results}

To obtain more precise data on sexually dimorphic gene expression in the adrenal glands of adult male and female rats, we performed analyses of the samples of the $\mathrm{ZG}$ and $\mathrm{ZF} / \mathrm{R}$ of the glands. Due to the nature of the applied experiment, all data were analyzed in relation to the adrenal glands of the male rats. The mean expression value of each gene was presented in scatter plot graphs (Fig. 1). The left upper part of the graphs shows genes, the expression levels of which were higher in the female than in the male adrenal glands. In the right lower part of the graphs, genes are also shown, the expression levels of which were lower in the female than in the male adrenal glands. By applying the previously mentioned cut-off parameters (fold change $\pm 2 ; p<0.05$ ), the Affymetrix Rat Gene 1.1 ST Array data revealed 32 differentially expressed genes in the
$\mathrm{ZG}$, and 233 genes in the ZF/R. A Venn diagram demonstrated their localization to the adrenocortical zones examined (Fig. 2). Of these, in the ZG only 15 , while in the $\mathrm{ZF} / \mathrm{R} 216$ genes were exclusively expressed; 17 genes were regulated both in the ZG and $\mathrm{ZF} / \mathrm{R}$. In the $\mathrm{ZG}$, the expression levels of 24 genes were lower and 8 were higher in the female rats. More pronounced sex-related differences were observed in the $\mathrm{ZF} / \mathrm{R}$. In this compartment of the rat adrenal cortex, the expression levels of 146 genes were lower and those of 87 genes were higher in the female rats. In both the $\mathrm{ZG}$ and $\mathrm{ZF} / \mathrm{R}$, the expression levels of 10 genes were lower and 7 were higher in the female rats.

We also identified transcripts with differential expression in the $\mathrm{ZG}$ and $\mathrm{ZF} / \mathrm{R}$ of adult male and female rats (Fig. 2). In male rats, compared to the $\mathrm{ZF} / \mathrm{R}$, in the $\mathrm{ZG} 448$ genes were upregulated and 123 downregulated. In females, these figures were 519 and 183 , respectively.

Each of the raw expression values from gender-specific genes was grouped using a hierarchical clustering algorithm. The results of this analysis are presented as a heat map (Fig. 3). The clustering confirmed that in the ZG, the expression levels of 24 genes were lower and 8 were higher in the female rats and the symbols of these genes are shown. The same applied to the $\mathrm{ZF} / \mathrm{R}$; however, in this compartment, the expression levels of 146 genes were lower and those of 87 genes were higher in the female rats.

Subsequently, we performed SEA followed by functional analysis using the GeneAnswers package of Bioconductor which, among other things, allows us to interpret a list of genes in the context of their participation in a certain particular biological process (GO.BP). The original results of GeneAnswer analysis (as of December 16, 2013) revealed 17 groups of genes with different functional profiles. These profiles were rather general (for example 'response to stimulus', 'response to chemical stimulus', 'response to organic substances') and the prevailing number of the obtained profiles were out of our interest (Fig. 4). It should be emphasized that the GO database is composed of some general, as well as specific categories with a similar meaning and, therefore, a single gene may be mapped to several GO terms and may be counted more than once. Moreover, GO 

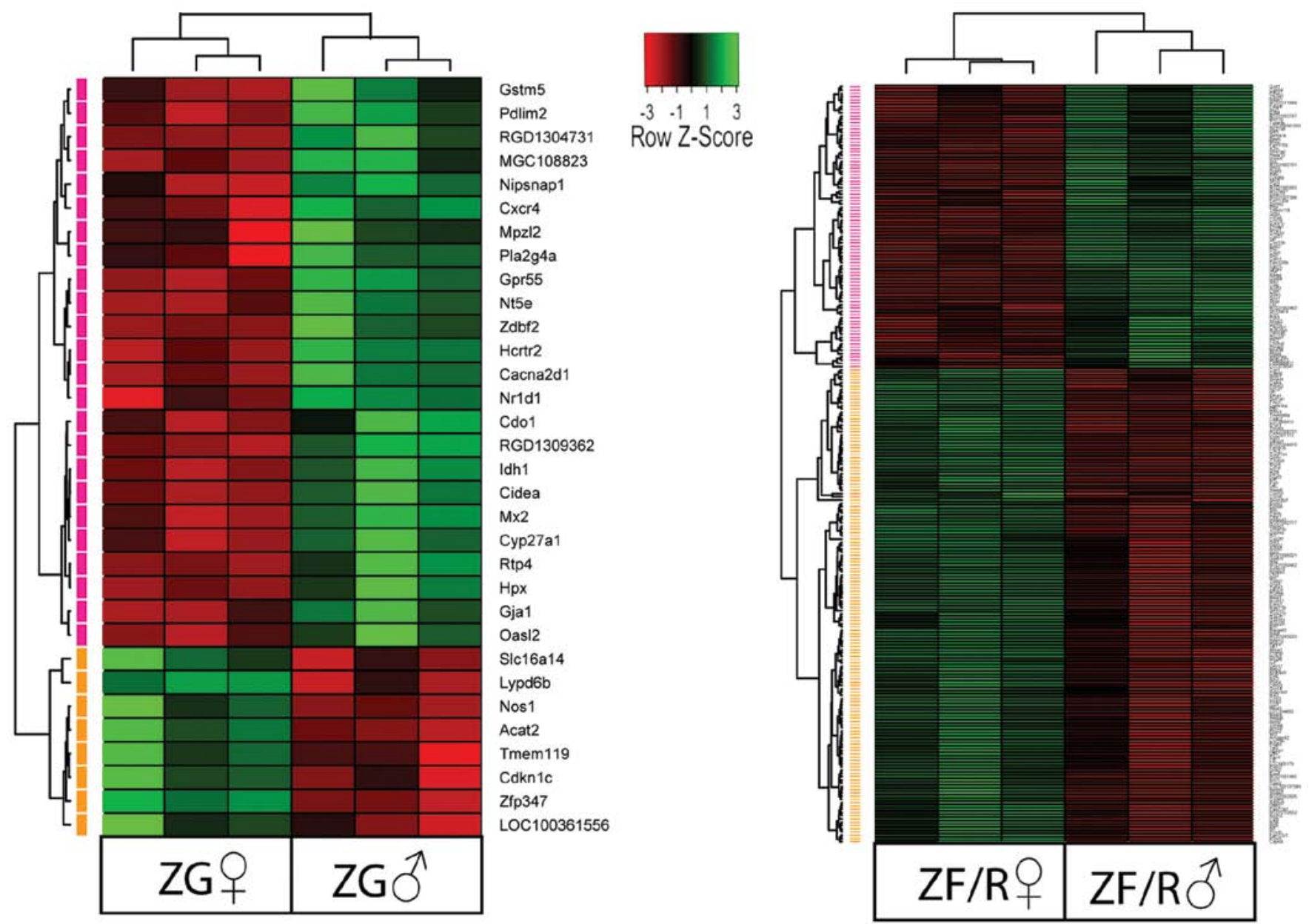

Figure 3. Heat map representation of microarray analysis for the gender-specific differentially expressed transcripts within the ZG and ZF/R of adult male and female rats. Arbitrary signal intensity acquired from microarray analysis is represented by colors. Studied genes were clustered by means of hierarchical clustering algorithm (green, higher; red, lower expression, in comparison to male gland). Hierarchical clustering was performed on log2 signal intensity data. These values were resized to Row Z-Score scale for any single genes (from -3 , the lowest expression to +3 , the highest expression). ZG, zona glomerulosa; ZF/R, zona fasciculata/reticularis.

functional annotations of genes are still in the developing stage and are far from complete. Since this analysis yielded rather unsatisfactory results, we decided to analyze our results using the DAVID system.

The DAVID system is a powerful tool that allows us to discover enriched functionally related gene groups and to cluster similar annotation terms. This system extracts data from numerous databases and, as evidenced by the Science Citation Index, this system is gaining wide popularity among molecular biologists. We performed separate analyses for the $\mathrm{ZG}$ and $\mathrm{ZF} / \mathrm{R}$. For the $\mathrm{ZG}$, with the selected cut-off value $(\mathrm{p}<0.05), 3$ annotation clusters were obtained (ordered by enrichment score) (Table II). On the other hand, for the ZF/R 5 clusters were obtained. All clusters (ZG and ZF/R) combined 516 genes (counts). This figure indicated that numerous genes participated in more than one annotation cluster. In the $\mathrm{ZG}$ 90 counts were either up- or downregulated, while in the $\mathrm{ZF} / \mathrm{R}$ the number of counts was notably higher, i.e., 426.

For the ZG, annotation clusters 1 and 2 combined genes involved in the regulation of ion transport, while cluster 3 contained transcripts linked to response to hormones (Table II).
In the case of $\mathrm{ZF} / \mathrm{R}$, we obtained 5 clusters. The first cluster combined genes regulating steroid biosynthesis and metabolism. Cluster 2 incorporated genes primarily connected with cell fractions, while annotation cluster 3 (with 13 subclusters) combined transcripts primarily connected with oxidation/ reduction processes. Cluster 4 was composed of genes regulating responses to nutrients and to extracellular stimuli or steroid hormone stimuli. Annotation cluster 5 also contained genes involved in response to stimuli, among which were 'response to hormone stimulus' (subcluster 2) and 'response to peptide hormone stimulus' (subcluster 7).

Subsequently, we analyzed a list of genes which were differentially expressed in the $\mathrm{ZG}$ and $\mathrm{ZF} / \mathrm{R}$ of the adrenal glands in adult female rats, in comparison to adult male rats and annotated as a 'response to hormone stimulus' (for the ZG from cluster 3, and for ZF/R from cluster 5 shown in Table II). Of these genes, the expression levels of cysteine dioxygenase type 1 (Cdo1), gap junction protein, alpha 1 (Gja1), isocitrate dehydrogenase 1 (Idh1) and phospholipase A2, group IVA (Pla2g4a) were lower and those of nitric oxide synthase 1 (Nos1) were higher in the ZG of female rats, when compared 
Table II. Functional annotation clustering report of differentially expressed genes in the $\mathrm{ZG}$ and $\mathrm{ZF} / \mathrm{R}$ of adult male and female rats, as revealed by DAVID analysis (separate analyses for ZG and $\mathrm{ZF} / \mathrm{R})$.

\begin{tabular}{lrr}
\hline Gene function & Up & Down \\
\hline Zona gromelurosa & $\downarrow$ & $\uparrow$ \\
\hline Annotation cluster 1/enrichment score: 3.73 & & \\
Regulation of calcium ion transport & 3 & 1 \\
Regulation of metal ion transport & 3 & 1 \\
Regulation of ion transport & 3 & 1 \\
Annotation cluster 2/enrichment score: 2.32 & & \\
Iron ion binding & 4 & 1 \\
Metal binding & 8 & 1 \\
Transition metal ion binding & 8 & 2 \\
Metal ion binding & 10 & 2 \\
Cation binding & 10 & 2 \\
Iron & 3 & 1 \\
Ion binding & 10 & 2 \\
Annotation cluster 3/enrichment score: 2.2 & & \\
Response to hormone stimuli & 4 & 1 \\
Response to endogenous stimuli & 4 & 1 \\
Response to steroid hormone stimuli & 3 & 1 \\
\hline
\end{tabular}

Zona fasciculata/reticularis

Annotation cluster 1/enrichment score: 4.66

Steroid metabolic process

Cholesterol metabolic process

Sterol metabolic process

Steroid biosynthetic process

Lipid biosynthetic process

Steroid biosynthesis

Annotation cluster 2/enrichment score: 3.75

Microsome

Vesicular fraction

Insoluble fraction

Membrane fraction

Cell fraction

Annotation cluster 3/enrichment score: 2.99

Oxidation reduction

Oxidoreductase

Monooxygenase

Electron carrier activity

Cytochrome P450, C terminal region

Cytochrome P450

Secondary metabolites biosynthesis, transport and catabolism

Iron ion binding

Iron

Cytochrome P450, conserved site

Chromoprotein

Metalloprotein

Cytochrome P450, E class, group I
Table II. Continued.

\begin{tabular}{lrr}
\hline Gene function & Up & Down \\
\hline Zona fasciculata/reticularis & $\downarrow$ & $\uparrow$ \\
\hline Annotation cluster 4/enrichment score: 2.94 & & \\
Response to extracellular stimulus & 7 & 7 \\
Response to nutrient levels & 6 & 6 \\
Response to nutrients & 4 & 6 \\
Response to steroid hormone stimuli & 6 & 5 \\
Annotation cluster 5/enrichment score: 2.6 & & \\
Response to organic substance & 17 & 11 \\
Response to hormone stimuli & 10 & 7 \\
Response to endogenous stimuli & 10 & 7 \\
Response to steroid hormone stimuli & 6 & 5 \\
Response to glucocorticoid stimuli & 4 & 3 \\
Response to corticosteroid stimuli & 4 & 3 \\
Response to peptide hormone stimuli & 5 & 4 \\
\hline
\end{tabular}

With the selected cut-off value $(\mathrm{p}<0.05)$, tree annotation clusters were obtained in the ZG and 5 in the ZF/R. In the table clusters being ordered by the enrichment score, the higher the score, the more enriched the gene. Modified Fisher exact 'p' values and 'p' from Benjamini and Hochberg's multiple testing correction are not shown. Up, upregulated; down, downregulated indicates higher or lower expression in relation to males. ZG, zona glomerulosa; $\mathrm{ZF} / \mathrm{R}$, zona fasciculata/reticularis.

with the males (Fig. 5). More pronounced differences were observed in the $\mathrm{ZF} / \mathrm{R}$ zones of the rat adrenal cortex. Of the 19 genes forming the above-mentioned subcluster, the expression levels of 7 of these genes were higher and those of 10 genes were lower in the female adrenal glands. In the female $\mathrm{ZF} / \mathrm{R}$, higher expression levels were observed in the following genes: alpha-2-macroglobulin (A2m), bone morphogenetic protein 7 (Bmp7), cytochrome P450, family 11, subfamily A, polypeptide 1 (Cyp11a1), insulin-like growth factor binding protein 2 (Igfbp2), Nos1, Nr0b1 and plasminogen activator, tissue (Plat). On the contrary, in the female ZF/R of the adrenal cortex, lower expression levels were observed in the following genes: $\mathrm{Cbl}$ proto-oncogene B, E3 ubiquitin protein ligase (Cblb), Cdo1, dihydropyrimidine dehydrogenase (Dpyd), forkhead box O1 (Foxo1), Gja1, Idh1, mucin 4, cell surface associated (Muc4), phosphoinositide-3-kinase, regulatory subunit 1 (alpha) (Pik3r1), sulfotransferase family, cytosolic, 1A, phenol-preferring, member 1 (Sult1a1) and transforming growth factor, beta receptor III (Tgfbr3).

Furthermore, analyses of ZF/R genes represented in cluster 1, subcluster 'steroid metabolism process' (from Table II) revealed numerous genes, the expression levels of which were different in the $\mathrm{ZF} / \mathrm{R}$ (Fig. 6). Of these genes, the expression levels of only 4 of them [ATP-binding cassette, sub-family A (ABC1), member 1 (Abca1), cytochrome P450, family 27, subfamily A, polypeptide 1 (Cyp27a1), lipase, hormone-sensitive (Lipe) and Sultlal] were lower in the females compared to the males. On the contrary, the remaining genes exhibited higher expression levels in the females [Cyp11a1, cytochrome P450, family 11, subfamily B, polypeptide 1 (Cyp11b1), cytochrome P450, 
FUNCTIONAL PROFILES: ZG ZF/R

\begin{tabular}{|c|c|c|c|}
\hline Minimum & Response to stimulus & 20 & 99 \\
\hline 0.00138 & Response to chemical stimulus & 13 & 54 \\
\hline 0.0535 & Response to stress & 13 & 48 \\
\hline & Defense response & 8 & 11 \\
\hline & Response to other organism & 6 & 10 \\
\hline & Response to biotic stimulus & 6 & 10 \\
\hline & Inflammatory response & 5 & 6 \\
\hline & Response to interferon-gamma & 3 & 3 \\
\hline & Response to organic substance & 9 & 41 \\
\hline & Multi-organism process & 7 & 19 \\
\hline & Lysine catabolic process & 0 & 3 \\
\hline & Lysine metabolic process & 0 & 3 \\
\hline & Cellular amino acid catabolic process & 2 & 7 \\
\hline & Purine nucleobase catabolic process & 0 & 2 \\
\hline & Positive regulation of cell adhesion & 0 & 7 \\
\hline & Regulation of signal transduction & 7 & 35 \\
\hline & Signal transduction & 10 & 68 \\
\hline & Genes / Group & 31 & 219 \\
\hline
\end{tabular}

Figure 4. Functional profiles of differentially expressed genes determine by the GeneAnswers package (as of December 16, 2013), based on the Gene Ontology Biological Process (GO.BP) database. Presented numbers show quantity of genes (identified in the present study) which are involved in described biological processes (functional profiles). Genes were analyzed from both male and female adrenal glands. Grey background marks functional groups of genes with statistically significant differences (hypergeometric test, $\mathrm{p}<0.05$ ). ZG, zona glomerulosa; ZF/R, zona fasciculata/reticularis.

\begin{tabular}{|c|c|c|c|}
\hline GENE SYMBOL & GENE NAME & ZG (fold) & ZF/R (fold) \\
\hline Cblb & Cas-Br-M (murine) ecotropic retroviral transforming sequence b & ns & $\downarrow 2.84$ \\
\hline A2m & Alpha-2-macroglobulin & ns & $\uparrow \mathbf{3 . 1 5}$ \\
\hline Bmp7 & Bone morphogenetic protein 7 & ns & 个 2.15 \\
\hline Cdo1 & Cysteine dioxygenase, type I & $\downarrow \mathbf{3 . 1 6}$ & $\downarrow 2.04$ \\
\hline Cyp11a1 & Cytochrome P450, family 11, subfamily a, polypeptide 1 & ns & $\uparrow 2.4$ \\
\hline Dpyd & Dihydropyrimidine dehydrogenase & ns & $\downarrow \mathbf{2 . 2 7}$ \\
\hline Foxo1 & Forkhead box 01 & ns & $\downarrow \mathbf{2 . 4 2}$ \\
\hline Gja1 & Gap junction protein, alpha 1 & $\downarrow 2.02$ & $\downarrow 2.99$ \\
\hline Igfbp2 & Insulin-like growth factor binding protein 2 & ns & $\uparrow 3.24$ \\
\hline Idh1 & Isocitrate dehydrogenase 1 (NADP+), soluble & $\downarrow 2.93$ & $\downarrow \mathbf{3 . 5 7}$ \\
\hline Muc4 & Mucin 4, cell surface associated & ns & $\downarrow 2.16$ \\
\hline Nos1 & Nitric oxide synthase 1, neuronal & $\uparrow 2.88$ & $\uparrow 2.96$ \\
\hline NrOb1 & Nuclear receptor subfamily 0, group B, member 1 & ns & $\uparrow 2.2$ \\
\hline Pik3r1 & Phosphoinositide-3-kinase, regulatory subunit 1 (alpha) & ns & $\downarrow \mathbf{2 . 8 6}$ \\
\hline Pla2g4a & Phospholipase A2, group IVA (cytosolic, calcium-dependent) & $\downarrow \mathbf{2 . 2 6}$ & ns \\
\hline Plat & Plasminogen activator, tissue & ns & $\uparrow 2.8$ \\
\hline Star & Steroidogenic acute regulatory protein & ns & 个2.16 \\
\hline Sult1a1 & Sulfotransferase family, cytosolic, 1A, phenol-preferring, member 1 & ns & $\downarrow \mathbf{3 . 2 6}$ \\
\hline Tgfbr3 & Transforming growth factor, beta receptor III & ns & $\downarrow \mathbf{2 . 2 8}$ \\
\hline
\end{tabular}

Figure 5. List of genes represented in cluster 3, 'response to hormone stimulus' (ZG) and cluster 5, subcluster 'response to hormone stimulus' (ZF/R) (shown in Table II, DAVID analysis) which are differentially expressed in the ZG and ZF/R of adrenal glands of adult female rats, in comparison to adult male rats. Downward-facing arrowhead indicates a lower expression in females than in males; upward-facing arrowhead indicates a higher expression in females than in males; ns, differences statistically not significant; ZG, zona glomerulosa; ZF/R, zona fasciculata/reticularis. 


\begin{tabular}{|c|c|c|c|}
\hline GENE SYMBOL & GENE NAME & ZG (fold) & ZF/R (fold) \\
\hline Abca 1 & ATP-binding cassette, sub-family A (ABC1), member 1 & ns & $\downarrow \mathbf{5 . 5 1}$ \\
\hline Cyp11a1 & cytochrome P450, family 11, subfamily a, polypeptide 1 & ns & $\uparrow 2.4$ \\
\hline Cyp27a1 & cytochrome P450, family 27, subfamily a, polypeptide 1 & $\downarrow 2.4$ & $\downarrow \mathbf{3 . 3}$ \\
\hline Cyp11b1 & cytochrome P450, subfamily 11B, polypeptide 1 & ns & $\uparrow 2.37$ \\
\hline Cyp51 & cytochrome P450, subfamily 51 & ns & $\uparrow 2.5$ \\
\hline Fabp6 & fatty acid binding protein 6 , ileal & ns & $\uparrow 4.45$ \\
\hline Hsd17b7 & hydroxysteroid (17-beta) dehydrogenase 7 & ns & $\uparrow 2.46$ \\
\hline Idi1 & isopentenyl-diphosphate delta isomerase 1 & ns & $\uparrow 4.2$ \\
\hline Lss & Ianosterol synthase (2,3-oxidosqualene-lanosterol cyclase) & ns & $\uparrow \mathbf{2 . 2 5}$ \\
\hline Lipe & lipase, hormone sensitive & ns & $\downarrow 2.1$ \\
\hline NrOb1 & nuclear receptor subfamily $\mathbf{0}$, group B, member 1 & ns & $\uparrow 2.2$ \\
\hline Sqle & squalene epoxidase & ns & $\uparrow \mathbf{2 . 8 7}$ \\
\hline Star & steroidogenic acute regulatory protein & ns & $\uparrow 2.16$ \\
\hline Sult1a1 & sulfotransferase family, cytosolic, 1A, phenol-preferring, member 1 & ns & $\downarrow \mathbf{3 . 2 6}$ \\
\hline
\end{tabular}

Figure 6. List of genes represented in ZF/R cluster 1, subcluster 'steroid metabolic process' (shown in Table II, DAVID analysis) and which are differentially expressed in the ZG and ZF/R of adrenal glands of adult female rats, in comparison to adult male rats. Downward facing arrowhead indicates a lower expression in females than in males; upward-facing arrowhead indicates a higher expression in females than in males; ns, differences statistically not significant; ZG, zona glomerulosa; $\mathrm{ZF} / \mathrm{R}$, zona fasciculata/reticularis.

family 51 (Cyp51), fatty acid binding protein 6, ileal (Fabp6), hydroxysteroid (17-beta) dehydrogenase 7 (Hsd17b7), isopentenyl-diphosphate delta isomerase 1 (Idi1), lanosterol synthase (2,3-oxidosqualene-lanosterol cyclase) (Lss), $\mathrm{NrOb1}$, squalene epoxidase (Sqle) and steroidogenic acute regulatory protein (Star)].

By means of RT-qPCR, we also validated the expression levels of selected genes with gender-specific differences in their expression levels in the $\mathrm{ZG}$ and/or $\mathrm{ZF} / \mathrm{R}$ of adult male and female rat adrenal glands (Fig. 7). In all cases, the results of RT-qPCR confirmed the differences revealed by the Affymetrix ${ }^{\circledR}$ Rat Gene 1.1 ST Array. The expression levels of Star, Cyp11a1 and NrOb1 were notably higher in the ZF/R of the female rats, while no differences were observed in the ZG. No sex-related differences were observed in the expression levels of cytochrome $\mathrm{P} 450$, family 11 , subfamily B, polypeptide 2 (Cyp11b2) in the ZG, while the expression level Cyp11b1 was notably higher in the female $\mathrm{ZF} / \mathrm{R}$. Lipe mRNA levels were notably higher in the male $\mathrm{ZF} / \mathrm{R}$, while in the $\mathrm{ZG}$ its expression was similar in both genders. Moreover, in both the $\mathrm{ZG}$ and $\mathrm{ZF} / \mathrm{R}$, the expression levels of hypocretin (orexin) receptor 2 (Hcrtr2) were notably lower in the female than in the male adrenal glands.

\section{Discussion}

Global gene expression profiling allows for a simultaneous analysis of thousands of genes in a single sample. This powerful tool of molecular biology is widely used, among others, in studies on basic biology or in the diagnosis of various diseases. This method has also been used in studies on adrenal glands. In recent years increasing amounts of data linking gene expression with adrenal biology have been generated. In this area, the first reports were focused on gene profiles for steroidogenic enzymes in adrenocortical diseases, in particular in aldosterone-producing adenomas and other adrenocortical tumors (29-34). Gene profiling methods applied to freshly isolated adrenocortical cells or established cell lines (Y1, H295R human adrenocortical cells), allows the identification of numerous genes involved in the regulation of adrenocortical growth and functioning and provides novel data on intracellular pathways involved in the regulation of aldosterone and corticosterone secretion $(13,35,36)$

Transcriptional profiling has also been used in in vivo experiments. By means of this method, the circadian regulation of steroid hormone biosynthesis genes was examined in the rat adrenal gland (37). In knockout mice lacking Star, numerous up- and downregulated genes were identified by Ishii et al (38). Furthermore, recent studies on the regulation of the renin-angiotensin-aldosterone system (RAAS) in rat adrenal glands identified transcripts involved in RAAS activation (39). Transcriptional profiling has also been applied for the characterization of enucleation-induced adrenal regeneration in the rat (21-23).

From the above short survey, it appears that in in vivo experiments, gene profiling methods are used mainly for investigations of adrenal glands with experimentally modified function. Not considering studies on the circadian regulation of steroid hormone biosynthesis genes, to the best of our knowledge, only one study has been performed on the intact rat adrenal gland (14). The authors investigated differentially expressed transcripts in the adrenal $\mathrm{ZG}$ and $\mathrm{ZF}$ of the adult male rat. It appeared that in the $Z G, 235$ transcripts were upregulated by $>2$-fold compared to $\mathrm{ZF}$ and 231 transcripts were upregulated in the ZF (14). We performed a similar analysis of the adrenal glands of adult male and female rats. In our study, in both genders the number of differentially expressed transcripts in the adrenal $\mathrm{ZG}$ and $\mathrm{ZF} / \mathrm{R}$ was notably higher than that previously reported for the $\mathrm{ZG}$ and $\mathrm{ZF}$ of male rats (14). The study by Nishimoto et al (14) identified 466 such transcripts, while the figures obtained in the present study amounted to 571 for male and 702 for female rats. These differences may be due to the various methods applied in two studies, as there are many methods gerenarally used (40-42). 


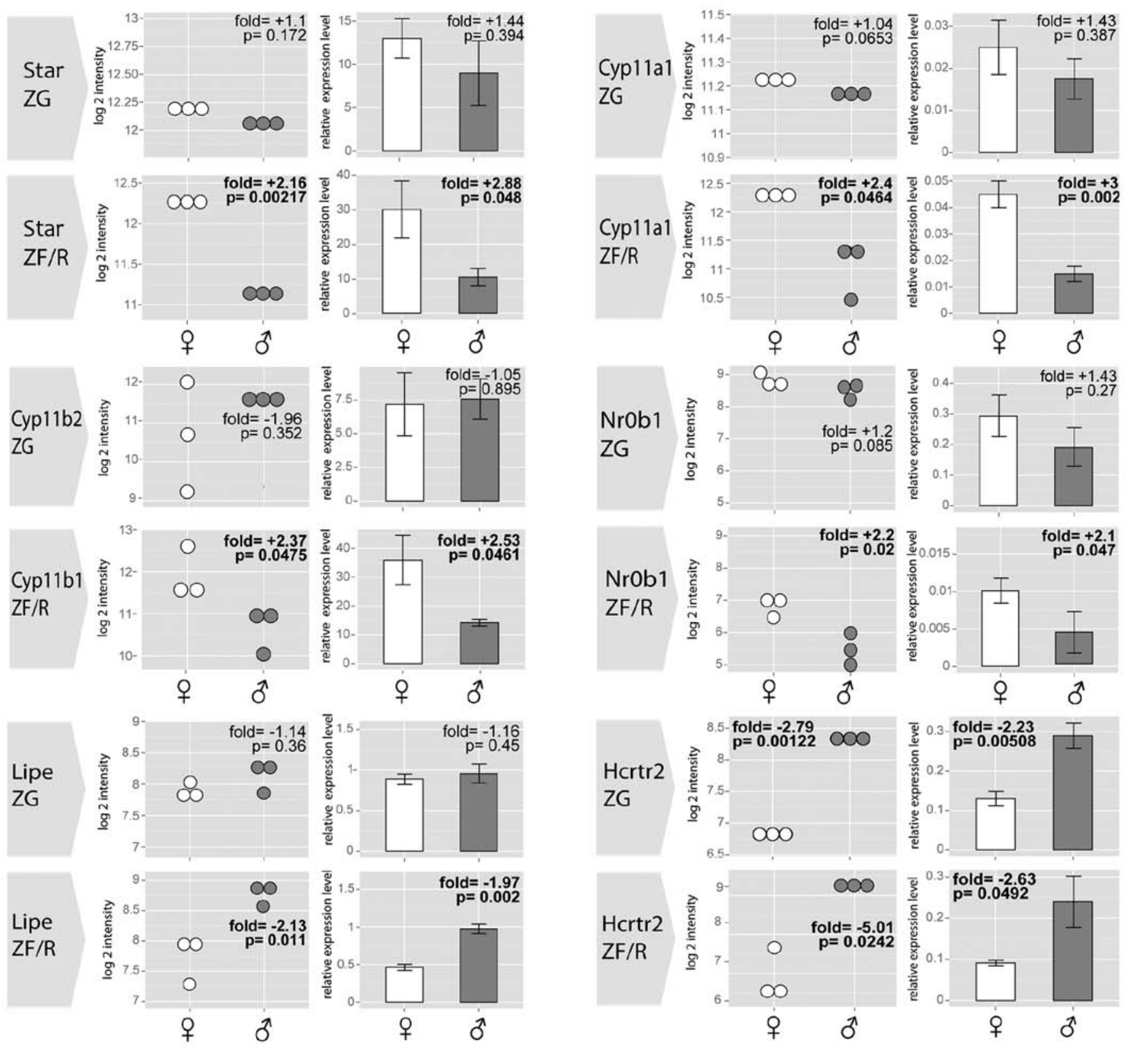

Figure 7. Results of RT-qPCR validation for selected genes with gender-specific differences in their expression levels in the $\mathrm{ZG}$ and $\mathrm{ZF} / \mathrm{R}$ of adult male and female rats. Dot plots present data obtained from Affymetrix ${ }^{\circledR}$ Rat Gene 1.1 ST Array, bar plots present the means \pm SE from RT-qPCR. Eeach group $n=3$. Data are in comparison to male adrenal glands. Fold changes and p-values are shown. Star - steroid acute regulatory protein; Cyp11a1, cytochrome P450, family 11, subfamily A, polypeptide 1; Cyp11b2, cytochrome P450, family 11, subfamily B, polypeptide 2; Cyp11b1, cytochrome P450, family 11, subfamily B, polypeptide 1; Lipe, hormone sensitive lipase; NrOb1, nuclear receptor subfamily 0, group B, member 1; Hcrtr2, hypocretin (orexin) receptor 2; ZG, zona glomerulosa; $\mathrm{ZF} / \mathrm{R}$, zona fasciculata/reticularis.

We used Affymetrix GeneChip ${ }^{\circledR}$ WT Terminal Labeling and the Hybridization system, while Nishimoto et al applied the Illumina platform; we sampled fresh tissue (vs. frozen), used the RMA algorithm (vs. the percentile shift method) and our experiment was performed on Wistar rats (vs. the SpragueDawley strain) [we have also used Wistar rats in a previous study (43)]. Furthermore, the study by Nishimoto et al (14) obtained samples by means of a very precise laser-capture microdissection method, while our samples contained cells of both the zona fasciculata and reticularis (ZF/R). This means that our zona fasciculata cells were contaminated with the zona reticularis ones. Be as it may, our data also revealed notable differences in the number of differentially expressed transcripts in the adrenal glands of adult male and female rats, and in females this number was significantly higher.

It is well known that in the rat, the structure and function of the adrenal cortex exhibits sex-dependent differences (reviewed in refs. 4,5). The genetic background of these differences is little known, therefore we performed whole transcriptome analyses on the adrenal glands of mature male and female rats which allowed as to compare the expression levels of approximately 27,000 genes by applying microarray technology. In the adrenal cortex of the examined rats, in both the $\mathrm{ZG}$ and $\mathrm{ZF} / \mathrm{R}$, we identified 265 differentially expressed 
genes (male vs. female) and this figure is comparable to data previously reported for mice (269 genes regulated in the female adrenal compared to the male gland, and analyses were performed on the entire glands with Agilent array) (16). Our analysis revealed that the most pronounced sex-related differences in gene expression in the rat adrenal cortex were present in the $\mathrm{ZF} / \mathrm{R}$. In this compartment, the expression levels of 146 sex-regulated genes were lower in the female than in the male gland.

To describe the functions of differentially expressed genes in the male and female rat adrenal cortex, we performed the clustering of identified transcripts. By using DAVID tool, in the ZG, 3 annotations clusters were obtained and they were mainly related to ion transport and the response to endogenous stimuli. Unexpectedly, the expression levels of these genes were notably lower in the female rats. In the $\mathrm{ZF} / \mathrm{R}$, on the other hand, 5 annotation clusters with various numbers of subclusters were obtained. Of these, only in annotation cluster 1 (combining genes regulating steroid biosynthesis and metabolism) the numbers of upregulated transcripts in the female adrenal glands were higher than those in the male $\mathrm{ZF} / \mathrm{R}$. In the 4 remaining clusters, the numbers of downregulated transcripts in female adrenal glands were higher than those of the upregulated transcripts. These findings suggest the higher steroidogenic activity of the female than the male $\mathrm{ZF} / \mathrm{R}$ and are in line with the findings of previous studies showing higher corticosterone secretion by the adrenal glands of female rats $(4,5)$. Moreover, these observations are in accordance with those of previous studies, showing that stimulation of the highly-specialized function of adrenocortical cells (i.e., steroid hormone release) is always coupled with the inhibition or lowering of their basal biological processes, for instance the proliferation rate (44-46).

As revealed by DAVID analysis, the differentially expressed genes were significantly enriched in sets of genes involved in steroid hormone metabolism and their expression levels in the $\mathrm{ZF} / \mathrm{R}$ of adult female rats were significantly higher than those in male adrenal glands. On the contrary, DAVID analysis did not reveal this group of transcripts in the ZG. Thus, the group of genes directly involved in steroid hormone synthesis expresses a sexually dimorphic pattern in the rat $\mathrm{ZF} / \mathrm{R}$, but not $\mathrm{ZG}$. In this regard, the study by El Wakil et al (16) on sexual dimorphism of gene expression in the mouse adrenal gland revealed only 2 genes (Nr5a1 and NrOb1) differentially expressed in the mouse, with higher expression levels in females. However, in their study none of the genes directly involved in steroid biosynthesis was found to be differentially expressed (16). We confirmed their findings on genes encoding known transcription factors and in the case of $\mathrm{NrOb1}$, we demonstrated that this difference was due to its higher expression in the $\mathrm{ZF} / \mathrm{R}$, but not in the ZG. Furthermore, the present study revealed that in the female $\mathrm{ZF} / \mathrm{R}$ of the rat, there were higher expression levels of Cyp11a1, Cyp11b1, Fabp6, Hsd17b7, Idi1 and Star. These differences may be dependent on the species (rat vs. mouse) and the method of sampling, e.g., the separate anlaysis of the $\mathrm{ZG}$ and $\mathrm{ZF} / \mathrm{R}$ in our study as opposed to the analysis of the entire glands in mice.

In contrast to 'steroidogenic' genes, in the female $\mathrm{ZF} / \mathrm{R}$, prevailing numbers of genes linked to cell fraction, oxidation/reduction processes and response to nutrients, as well as to extracellular stimuli or steroid hormone stimuli were found to be downregulated. Also this finding is rather unexpected, it seems to be scientifically justified (the negative interrelationship between highly specialized cell function and basic cell functions).

In present study, the expression levels of selected genes involved in the regulation of steroid biosynthesis was validated by RT-qPCR. As is known, cholesterol is the precursor for the entire adrenal steroidogenesis. Cholesterol may originate from different sources: i) de novo synthesis in the endoplasmic reticulum from acetyl CoA, ii) the mobilization of cholesteryl esters stored in lipid droplets through cholesteryl ester hydrolase, iii) plasma lipoprotein-derived cholesteryl esters obtained by either low-density lipoprotein (LDL) receptormediated endocytosis and/or scavenger receptor class $\mathrm{B}$ type I (SR-BI)-mediated selective uptake $(47,48)$. Earlier data have demonstrated that the concentration of total lipids, total cholesterol, phospholipids and glycerides is similar in the adrenal glands of adult male and female rats; however their content, due to larger adrenal glands, is markedly higher in females (49). In this regard, Lipe is a major cholesterol hydrolase of the adrenal glands $(50,51)$. The specific activity of this enzyme in $105,000 \mathrm{~g}$ supernatant of adrenal homogenates is higher in male than in female rats (52). In the present study, we demonstrated higher Lipe mRNA levels in the male $Z F / R$, while in the $\mathrm{ZG}$ the expression was similar in both genders. Thus, in the male ZF/R the higher activity of Lipe is accompanied by higher expression levels of the Lipe gene. Moreover, we demonstrated that the expression of the Lipe gene in the rat ZG was similar in both genders.

It has been well documented that the Star gene encodes a protein involved in the acute regulation of steroid hormone synthesis. This protein is responsible for the transport of cholesterol from the outer to the inner mitochondrial membrane (53). Earlier immunohistochemical and immunofluorescence studies have revealed the presence of Star protein in both the ZG and ZF/R of the rat adrenal cortex (54-57). In the mouse adrenal glands, Star mRNA levels (assessed by RT-PCR) have been reported be slightly higher in males than in females, although the differences were not statistically significant (58). In the present study, the mRNA expression levels of Star were notably higher in the $\mathrm{ZF} / \mathrm{R}$ of female rats, while no differences were observed in the ZG. To the best of our knowledge, this is the first demonstration of specific sexrelated differences in Star gene expression in the rat adrenal cortex.

Cyp11a1 encodes the P450scc enzyme (cholesterol 20-22 desmolase) that catalyzes the first and rate-limiting step of steroid biosynthesis $(59,60)$. This enzyme is expressed in all adrenocortical zones $(14,61)$. As previously reported, the rate of cholesterol transformation into pregnenolone (side chain cleavage activity) is markedly lower in male than in female rats $(2,62,63)$. Moreover, the levels of adrenodoxin in decapsulated (i.e., devoid of ZG cells) adrenal glands have been reported to be lower in male than in female rats (64). In this study, we revealed the higher expression of the Cyp1lal gene in the $\mathrm{ZF} / \mathrm{R}$ of female rats. Again, as in the case of the Star gene, the mRNA levels of Cyp11al were comparable in the ZG of adult male and female rats. Thus, the previously reported higher rate of pregnenolone synthesis in the female rat adrenal 
cortex depends on the higher expression of the Cyplla1 gene and the $\mathrm{ZF} / \mathrm{R}$ compartment of the cortex is responsible for these differences.

We also validated the expression levels of 2 genes coding enzymes of the steroidogenic late pathway in the rat, Cyp1 1b2 (aldosterone synthase, responsible for aldosterone synthesis) and Cyp11b1 (steroid 11beta-hydroxylase, responsible for corticosterone synthesis). In situ hybridization and immunohistochemistry revealed the expression of aldosterone synthase in the rat ZG only $(14,61,65)$. These results are in agreement with those of a previous study which demonstrated (by RT-PCR) high expression levels of Cyp1lb2 in this zone (66). Our study confirmed these earlier observations. Moreover, we demonstrated that the expression levels of the Cyp11b2 gene were similar in the ZG of male and female rats. These data are in accordance with those of previous studies on the absence of sex-related differences in aldosterone synthesis in male and female rats (reviewed in Refs. 4,67). On the contrary, in the mouse adrenal glands, the mRNA levels of aldosterone synthase have been shown to be slightly higher in female than in male adrenal glands (58).

The Cyp11b1 gene encodes steroid 11beta-hydroxylase, which catalyzes the conversion of deoxycorticosterone to corticosterone. In the rat adrenal glands this enzyme is localized in the $\mathrm{ZF} / \mathrm{R}$ cells $(14,61)$. The activity of steroid 11beta-hydroxylase has been shown to be similar in adult male and female rats $(68,69)$. However, the level of cytochrome P- $450_{11 \beta}$, in the rat adrenal mitochondria has been shown to be lower in male than in female rats (64). In the present study, we demonstrated that the Cyp11b1 gene expression levels were notably higher in the female $\mathrm{ZF} / \mathrm{R}$, while no differences were observed in the $\mathrm{ZG}$ of the adrenal cortex.

Nr0b1 encodes the Dax1 protein (dosage-sensitive sex reversal, adrenal hypoplasia critical region, on chromosome X, gene 1) which is responsible for the development and maintenance of the steroidogenic axis (70-72). Experimental data have suggested that the DAX1 protein is a negative regulator of steroidogenesis. The sexually dimorphic expression of Dax-1 (NR0B1) in the mouse adrenal cortex has been observed by RT-PCR, western blotting and immunohistochemistry (73). It should be mentioned that in the mouse adrenal glands, the mRNA levels of Dax1 were only slightly higher in female than in male adrenals $(16,58)$. To the best of our knowledge, for the first time, we demonstrated that the expression levels of $\mathrm{Nr} 0 \mathrm{~b} 1$ were notably higher in the $\mathrm{ZF} / \mathrm{R}$ of female rats, while no differences were observed in the ZG.

In a series of experiments, the group of Jöhren et al (74-76) demonstrated a notable sex-dependent expression of Hcrtr2 in the rat adrenal cortex. They demonstrated that Hcrtr2 was localized in the ZG and zona reticularis, with higher expression levels in male adrenal gland. We confirmed these earlier studies, as in our study, the expression levels of Hcrtr2 in the $\mathrm{ZG}$ and $\mathrm{ZF} / \mathrm{R}$ were notably lower in the female than in the male adrenal glands. These results confirm the proper preparation of our tissue samples ( $\mathrm{ZG}$ and $\mathrm{ZF} / \mathrm{R}$ ) for the analysis presented in this study.

In conclusion, to the best of our knowledge, the present study presents the first report of sex-related gene expression profiles in the adrenal cortex of adult rats. The number of differentially expressed transcripts in the adrenal ZG and ZF/R was notably higher in the female than in the male rats (702 vs. 571). The differentially expressed genes were significantly enriched in sets of genes involved in steroid hormone metabolism and their expression levels in the $\mathrm{ZF} / \mathrm{R}$ of adult female rats were significantly higher than those in the male adrenal glands. In the female $\mathrm{ZF} / \mathrm{R}$, when compared with the male one, the prevailing numbers of genes linked to cell fraction, oxidation/ reduction processes, response to nutrients and to extracellular stimuli or steroid hormone stimuli were downregulated.

\section{Acknowledgements}

This study was financed from the funds of the National Science Centre (Poland) allocated on the basis of the decision number DEC-2013/11/B/NZ4/04746.

\section{References}

1. Bachmann R:Die Nebenniere.In:Handbuch der Mikroskopischen Anatomie des Menschen. Bargmann W (ed). Bd 6/5 Springer, Berlin Göttingen Heidelberg, pp1-952, 1954.

2. Kitay JI: Effects of estrogen and androgen on the adrenal cortex of the rat. In: Functions of the Adrenal Cortex. Vol 2, McKerns KW (ed). North Holland Publishing Corpany, Amsterdam, pp775-811, 1968.

3. Kime D, Vinson GP, Major P and Kilpatrick R: Adrenal-gonad relationship. In: Functions of the Adrenal Cortex. Vol 3. McKerns KW (ed). Academic Press, London, pp183-347, 1979.

4. Malendowicz LK: Cytophysiology of the mammalian adrenal cortex as related to sex, gonadectomy and gonadal hormones. PTPN Press, Poznan, pp1-233, 1994.

5. Goel N, Workman JL, Lee TT, et al: Sex differences in the HPA axis. Compr Physiol 4: 1121-1155, 2014.

6. Lescoat G, Jego P, Beraud G and Maniey J: Sex influences on the response of the hypothalamo-hypophysio-adrenal axis to emotional and systemic stress in the rat. 164: 2106-2113, 1970 (In French).

7. Le Mevel JC, Abitbol S, Beraud G and Maniey J: Temporal changes in plasma adrenocorticotropin concentration after repeated neurotropic stress in male and female rats. Endocrinology 105: 812-817, 1979.

8. Lesniewska B, Miskowiak B, Nowak M and Malendowicz LK: Sex differences in adrenocortical structure and function. XXVII. The effect of ether stress on ACTH and corticosterone in intact, gonadectomized, and testosterone- or estradiol-replaced rats. Res Exp Med (Berl) 190: 95-103, 1990.

9. Malendowicz LK: Sex differences in adrenocortical structure and function. I. The effects of postpubertal gonadectomy and gonadal hormone replacement on nuclear volume of adrenocortical cells in the rat. Cell Tissue Res 151: 525-536, 1974.

10. Malendowicz LK: Sex differences in adrenocortical structure and function. II. The effects of postpubertal gonadectomy and gonadal hormone replacement on the rat adrenal cortex evaluated by stereology at the light microscope level. Cell Tissue Res 151: 537-547, 1974.

11. Malendowicz LK, Robba C and Nussdorfer GG: Sex differences in adrenocortical structure and function. XXII. Light- and electron-microscopic morphometric studies on the effects of gonadectomy and gonadal hormone replacement on the rat adrenal cortex. Cell Tissue Res 244: 141-145, 1986.

12. Nussdorfer GG: Cytophysiology of the adrenal cortex. Int Rev Cytol 98: 1-405, 1986.

13. Schimmer BP, Cordova M, Cheng H, et al: Global profiles of gene expression induced by adrenocorticotropin in Y1 mouse adrenal cells. Endocrinology 147: 2357-2367, 2006.

14. Nishimoto K, Rigsby CS, Wang T, et al: Transcriptome analysis reveals differentially expressed transcripts in rat adrenal zona glomerulosa and zona fasciculata. Endocrinology 153: 1755-1763, 2012.

15. Nishimoto K, Rainey WE, Bollag WB and Seki T: Lessons from the gene expression pattern of the rat zona glomerulosa. Mol Cell Endocrinol 371: 107-113, 2013.

16. El Wakil A, Mari B, Barhanin J and Lalli E: Genomic analysis of sexual dimorphism of gene expression in the mouse adrenal gland. Horm Metab Res 45: 870-873, 2013. 
17. Dennis G Jr, Sherman BT, Hosack DA, et al: DAVID: database for annotation, visualization, and integrated discovery. Genome Biol 4: P3, 2003.

18. Huang W, Sherman BT and Lempicki RA: Systematic and integrative analysis of large gene lists using DAVID bioinformatics resources. Nat Protoc 4: 44-57, 2009.

19. Rucinski M, Andreis PG, Ziolkowska A, Nussdorfer GG and Malendowicz LK: Differential expression and function of beacon in the rat adrenal cortex and medulla. Int J Mol Med 16: 35-40, 2005.

20. Spinazzi R, Ziolkowska A, Neri G, et al: Orexins modulate the growth of cultured rat adrenocortical cells, acting through type 1 and type 2 receptors coupled to the MAPK p42/p44- and p38-dependent cascades. Int J Mol Med 15: 847-852, 2005.

21. Tyczewska M, Rucinski M, Trejter M, et al: Angiogenesis in the course of enucleation-induced adrenal regeneration - expression of selected genes and proteins involved in development of capillaries. Peptides 38: 404-413, 2012.

22. Tyczewska M, Rucinski M, Ziolkowska A, et al: Expression of selected genes involved in steroidogenesis in the course of enucleation-induced rat adrenal regeneration. Int J Mol Med 33: 613-623, 2014

23. Tyczewska M, Rucinski $M$ and Ziolkowska A: Enucleationinduced rat adrenal gland regeneration - expression profile of selected genes involved in control of adrenocortical cell proliferation. Int J Endocrinol 14: 130359, 2014.

24. Gentleman RC, Carey VJ, Bates DM, et al: Bioconductor: open software development for computational biology and bioinformatics. Genome Biol 5: R80, 2004.

25. Benjamini Y and Hochberg Y: Controlling the false discovery rate: A practical and powerful approach to multiple testing. J $\mathrm{R}$ Stat Soc B 57: 289-300, 1995.

26. Gene Ontology Consortium: The Gene Ontology project in 2008 Nucleic Acids Res 36: D440-D444, 2008.

27. Feng G, Shaw P, Rosen ST, et al: Using the bioconductor GeneAnswers package to interpret gene lists. Methods Mol Biol 802: 101-112, 2012.

28. Ashburner M, Ball CA, Blake JA, et al: Gene ontology: tool for the unification of biology. Nat Genet 25: 25-29, 2000.

29. Bassett MH, Mayhew B, Rehman K, et al: Expression profiles for steroidogenic enzymes in adrenocortical disease. J Clin Endocrinol Metab 90: 5446-5455, 2005.

30. Assie G, Auzan C, Gasc JM, et al: Steroidogenesis in aldosteroneproducing adenoma revisited by transcriptome analysis. J Clin Endocrinol Metab 90: 6638-6649, 2005.

31. Lenzini L, Seccia TM, Aldighieri E, et al: Heterogeneity of aldosterone-producing adenomas revealed by a whole transcriptome analysis. Hypertension 50: 1106-1113, 2007.

32. Giordano TJ, Kuick R, Else T, et al: Molecular classification and prognostication of adrenocortical tumors by transcriptome profiling. Clin Cancer Res 15: 668-676, 2009.

33. Wang T, Satoh F, Morimoto R, et al: Gene expression profiles in aldosterone-producing adenomas and adjacent adrenal glands. Eur J Endocrinol 164: 613-619, 2011.

34. Wilmot RH, Vezzosi D, Rizk-Rabin M, et al: Identification of gene expression profiles associated with cortisol secretion in adrenocortical adenomas. J Clin Endocrinol Metab 98: E1109-E1121, 2013.

35. Romero DG, Plonczynski MW, Welsh BL, et al: Gene expression profile in rat adrenal zona glomerulosa cells stimulated with aldosterone secretagogues. Physiol Genomics 32: 117-127, 2007.

36. Romero DG, Gomez-Sanchez EP and Gomez-Sanchez CE: Angiotensin II-regulated transcription regulatory genes in adrenal steroidogenesis. Physiol Genomics 42A: 259-266, 2010.

37. Oster H, Damerow S, Hut RA and Eichele G: Transcriptional profiling in the adrenal gland reveals circadian regulation of hormone biosynthesis genes and nucleosome assembly genes. J Biol Rhythms 21: 350-361, 2006.

38. Ishii T,Mitsui T, Suzuki S, et al: A genome-wide expression profile of adrenocortical cells in knockout mice lacking steroidogenic acute regulatory protein. Endocrinology 153: 2714-2723, 2012.

39. Nishimoto K, Harris RB, Rainey WE and Seki T: Sodium deficiency regulates rat adrenal zona glomerulosa gene expression. Endocrinology 155: 1363-1372, 2014

40. Tan PK, Downey TJ, Spitznagel EL, et al: Evaluation of gene expression measurements from commercial microarray platforms. Nucleic Acids Res 31: 5676-5684, 2003.

41. Barnes M, Freudenberg J, Thompson S, et al: Experimental comparison and cross-validation of the Affymetrix and Illumina gene expression analysis platforms. Nucleic Acids Res 33: 5914-5923, 2005.
42. Russ J and Futschik ME: Comparison and consolidation of microarray data sets of human tissue expression. BMC Genomics 11: 305, 2010

43. Malendowicz LK: Sex differences in adrenocortical structure and function. XXIV. Comparative morphometric studies on adrenal cortex of intact mature male and female rats of different strains. Cell Tissue Res 249: 443-449, 1987.

44. Ramachandran J and Suyama AT: Inhibition of replication of normal adrenocortical cells in culture by adrenocorticotropin. Proc Natl Acad Sci USA 72: 113-117, 1975.

45. Rybak SM and Ramachandran J: Primary culture of normal rat adrenocortical cells. I. Culture conditions for optimal growth and function. In Vitro 17: 599-604, 1981.

46. Dallman MF: Control of adrenocortical growth in vivo. Endocr Res 10: 213-242, 1984.

47. Hu J, Zhang Z, Shen WJ and Azhar S: Cellular cholesterol delivery, intracellular processing and utilization for biosynthesis of steroid hormones. Nutr Metab 7: 47, 2010.

48. Gallo-Payet N and Battista MC: Steroidogenesis-adrenal cell signal transduction. Compr Physiol 4: 889-964, 2014.

49. Malendowicz LK and Mlynarczyk W: Sex differences in adrenocortical structure and function. X. Lipid and corticosterone in the rat adrenal as affected by gonadectomy and testosterone or estradiol replacement. Endokrinologie 79: 292-300, 1982.

50. Boyd GS and Trzeciak WH: Cholesterol metabolism in the adrenal cortex: studies on the mode of action of ACTH. Ann NY Acad Sci 212: 361-377, 1973.

51. Kraemer FB, Shen WJ, Harada K, et al: Hormone-sensitive lipase is required for high-density lipoprotein cholesteryl ester-supported adrenal steroidogenesis. Mol Endocrinol 18: 549-557, 2004.

52. Trzeciak WH and Malendowicz LK: Sex differences in adrenocortical structure and function. VII. Adrenal sterol ester hydrolase activity in the rat and its dependence on gonadal hormones. Horm Metab Res 13: 519-522, 1981.

53. Stocco DM: StAR protein and the regulation of steroid hormone biosynthesis. Annu Rev Physiol 63: 193-213, 2001.

54. Kim YC, Ariyoshi N, Artemenko I, et al: Control of cholesterol access to cytochrome P450scc in rat adrenal cells mediated by regulation of the steroidogenic acute regulatory protein. Steroids 62: 10-20, 1997.

55. Lo YC, Brett L, Kenyon CJ, et al: StAR protein is expressed in both medulla and cortex of the bovine and rat adrenal gland. Endocr Res 24: 559-563, 1998.

56. Lehoux JG, Hales DB, Fleury A, et al: The in vivo effects of adrenocorticotropin and sodium restriction on the formation of the different species of steroidogenic acute regulatory protein in rat adrenal. Endocrinology 140: 5154-5164, 1999.

57. Rucinski M, Tortorella C, Ziolkowska A, et al: Steroidogenic acute regulatory protein gene expression, steroid-hormone secretion and proliferative activity of adrenocortical cells in the presence of proteasome inhibitors: in vivo studies on the regenerating rat adrenal cortex. Int J Mol Med 21: 593-597, 2008

58. Bastida CM, Cremades A, Castells MT, et al: Sexual dimorphism of ornithine decarboxylase in the mouse adrenal: influence of polyamine deprivation on catecholamine and corticoid levels. Am J Physiol 292: E1010-E1017, 2007.

59. Simpson ER, Mason JI, John ME, et al: Regulation of the biosynthesis of steroidogenic enzymes. J Steroid Biochem 27: 801-805, 1987.

60. Miller WL: Role of mitochondria in steroidogenesis. Endocr Dev 20: 1-19, 2011.

61. Ishimura $\mathrm{K}$ and Fujita $\mathrm{H}$ : Light and electron microscopic immunohistochemistry of the localization of adrenal steroidogenic enzymes. Microsc Res Tech 36: 445-453, 1997.

62. Colby HD and Kitay JI: Effects of gonadal hormones on adrenal steroid metabolism in vitro. Steroids 20: 143-157, 1972.

63. Malendowicz LK: Sex differences in adrenocortical structure and function. III. The effects of postpubertal gonadectomy and gonadal hormone replacement on adrenal cholesterol side chain cleavage activity and on steroids biosynthesis by rat adrenal homogenates. Endokrinologie 75: 311-323, 1976.

64. Brownie AC, Bhasker CR and Waterman MR: Levels of adrenodoxin, NADPH-cytochrome P-450 reductase and cytochromes P-45011 beta, P-45021, P-450scc, in adrenal zona fasciculata-reticularis tissue from androgen-treated rats. Mol Cell Endocrinol 55: 15-20, 1988.

65. Malee MP and Mellon SH: Zone-specific regulation of two messenger RNAs for P450c11 in the adrenals of pregnant and nonpregnant rats. Proc Natl Acad Sci USA 88: 4731-4735, 1991. 
66. Oaks MK and Raff H: Differentiation of the expression of aldosterone synthase and 11 beta-hydroxylase mRNA in the rat adrenal cortex by reverse transcriptase-polymerase chain reaction. J Steroid Biochem Mol Biol 54: 193-199, 1995.

67. Solyom J, Ludwig E, Regoly-Merei J and Vajda A: The effect of potassium ions in vitro upon steroid biosynthesis by rat adrenals. A study on the effect of different salt intake and sex difference. Endokrinologie 59: 249-259, 1972.

68. Ruhmann-Wennhold A and Nelson DH: Testosterone inhibition of estradiol-induced stimulation of adrenal 11-beta- and 18-hydroxylation. Proc Soc Exp Biol Med 133: 493-496, 1970.

69. Goldman AS, Gustafsson JA and Stenberg A: Neonatal imprinting of enzyme levels in rat adrenals. Acta Endocrinol (Copenh) 76: 719-728, 1974.

70. Beuschlein F, Keegan CE, Bavers DL, et al: SF-1, DAX-1, and acd: molecular determinants of adrenocortical growth and steroidogenesis. Endocr Res 28: 597-607, 2002.

71. Iyer AK and McCabe ER: Molecular mechanisms of DAX1 action. Mol Genet Metab 83: 60-73, 2004.
72. Manna PR, Dyson MT, Jo Y and Stocco DM: Role of dosagesensitive sex reversal, adrenal hypoplasia congenita, critical region on the $\mathrm{X}$ chromosome, gene 1 in protein kinase $\mathrm{A}$ - and protein kinase $\mathrm{C}$-mediated regulation of the steroidogenic acute regulatory protein expression in mouse Leydig tumor cells: mechanism of action. Endocrinology 150: 187-199, 2009.

73. Mukai T, Kusaka M, Kawabe K, et al: Sexually dimorphic expression of Dax-1 in the adrenal cortex. Genes Cells 7: 717-729, 2002.

74. Jöhren O, Neidert SJ, Kummer M, Dendorfer A and Dominiak P: Prepro-orexin and orexin receptor mRNAs are differentially expressed in peripheral tissues of male and female rats. Endocrinology 142: 3324-3331, 2001.

75. Jöhren O, Bruggemann N, Dendorfer A and Dominiak P: Gonadal steroids differentially regulate the messenger ribonucleic acid expression of pituitary orexin type 1 receptors and adrenal orexin type 2 receptors. Endocrinology 144: 1219-1225, 2003.

76. Jöhren O, Bruggemann N and Dominiak P: Orexins (hypocretins) and adrenal function. Horm Metab Res 36: 370-375, 2004. 